\title{
NARRATIVAS DE PROFESSORAS: EDUCAÇÃO/FORMAÇÃO CONTINUADA EM TEMPOS DE CENTRALISMO CURRICULAR
}

\author{
Valda Inês Fontenele Pessoa ${ }^{1}$ \\ Antônia Aparecida Lima Lopes ${ }^{2}$
}

RESUMO: O artigo foi construído a partir de um recorte das narrativas explicitadas em uma pesquisa desenvolvida no período 2017-2018 com professoras da rede municipal de educação do município de Rio Branco - Acre. É resultante de uma abordagem qualitativa de pesquisa, em que as fontes de informação foram professoras reunidas em um grupo focal, para narrarem suas percepções a respeito dos seus processos de educação/formação continuada. Participaram do grupo nove professoras, com idade entre 25 a 41 anos e tempo variável de efetivo exercício na profissão docente. O objetivo que norteou a pesquisa foi o de analisar narrativas de professoras sobre aspectos da educação/formação continuada que tiveram a oportunidade de participar, evidenciando as lógicas de organização e compreensão que perpassaram os processos orientadores da educação/formação da década recortada. A base teórica que orientou o estudo foi Benjamin (1985); Hall (1997); Bragança (2012); Ball (2005; 2002). Argumentamos, embasadas pelas narrativas das professoras, que nos percursos de educação/formação continuada são predominantes lógicas que estreitam a compreensão do que é ser professor, orientados pela perspectiva da performatividade e do gerenciamento dos resultados do trabalho do professor e da escola.

PALAVRAS-CHAVE: Narrativas. Educação-formação continuada. Performatividade.

\section{INTRODUÇÃo}

$\mathrm{O}$ artigo foi construído a partir de um recorte das narrativas explicitadas em uma pesquisa ${ }^{3}$ desenvolvida no período 2017-2018 com professoras da rede municipal de educação do município de Rio Branco - Acre. É resultante de uma abordagem qualitativa de pesquisa, em que as fontes de informação foram professoras reunidas em um grupo focal ${ }^{4}$, para narrarem suas percepções a respeito dos seus processos de educação/formação continuada. Participaram do grupo nove professoras, com idade entre 25 a 41 anos e tempo variável ${ }^{5}$ de efetivo exercício na profissão docente. O critério estabelecido para convidar as docentes para participarem do grupo, foi o de terem participado de uma série de encontros de formação continuada, ministrados pela equipe de técnicos da Secretaria Municipal de Educação - SEME entre os anos de 2006 a 2016, época em que a formação continuado de professores da educação infantil, ganhou um acentuado centralismo curricular, forjado pelas reformas públicas disseminadas no território brasileiro.

\footnotetext{
1 Doutora em Educação pela Pontifícia Universidade Católica de São Paulo, Professora do Programa de Pós-Graduação em Letras: linguagem e identidade da Universidade Federal do Acre. Lattes: http://lattes.cnpq.br/3182016462906419. ORCID: https//orcid.org/0000-0002-0276-0949. E-mail: valdapessoa@yahoo.com.br

2 Mestrado em Letras: linguagem e identidade pela Universidade Federal do Acre - UFAC, Professora do Curso de Pedagogia da Faculdade Fameta - Rio Branco/AC, nas áreas de Alfabetização, Letramento e Literatura Infanto Juvenil; Gestora do Centro de Educação Infantil Municipal Willy Viana das Neves. http://lattes.cnpq.br/5868812480702562 E-mail: antonialimalopes@ yahoo.com.br

$3 \mathrm{O}$ foco central da pesquisa desenvolvida pela pesquisadora Antônia Aparecida Lima Lopes para a realização do seu mestrado, estava delimitado nos aspectos formativos que envolviam o letramento, mas que diante das narrativas, houve a necessidade de abrir espaço de análise para os aspectos que envolvem e perpassam a concepção do desenho curricular vivenciado na educação/ formação continuada dessas professoras. Neste artigo, essas questões são aprofundadas, uma vez que as análises explicitadas na dissertação "Narrativas de professoras da educação infantil sobre letramento: lógica de formação continuada, se mostraram superficiais.

4 Segundo Gatti (2005, p. 9), grupo focal é uma técnica não diretiva de coleta que capta, a partir das interações entre os participantes do grupo, "conceitos, sentimentos, atitudes, crenças, experiências e reações" de uma maneira dificilmente obtida por outros meios procedimentais de coleta de informações de pesquisa. Também possibilita eclodir diferentes impressões sobre um mesmo aspecto e para além disso, faz emergir processos emocionais, possibilitados pelo conjunto de circunstâncias criadas, viabilizando a captação de significados, difíceis de serem expostos por outros meios (GATTI, 2005).

5 O tempo de serviço das professoras no magistério: 1 com 3 anos; 1 com 7 anos; 1 com 9anos; 2 com 11 anos; 3 com 16 anos e 1 com 22 anos.
} 
O encontro com as professoras, transcorreu em um espaço aconchegante, cedido pela gestora da escola Willy Viana das Neves. Em uma sala ampla, refrigerada e com cadeiras confortáveis, organizamos um círculo com as cadeiras para que facilitasse a interação entre as professoras. No canto da sala, dispusemos uma mesa com fotografias (acervo da escola) clicadas durante a década, em que as imagens apresentavam diversos encontros de formação, promovidos pela SEME. É importante ressaltar, que as nove professoras convidadas já haviam desenvolvido, em algum período das suas trajetórias, atividade docente naquele espaço escolar. A organização desse cenário foi pensado como estratégia de evocação das memórias, para que pudessem elaborar as narrativas orais dos episódios de formação, como também relembrar as pessoas que fizeram parte de suas histórias, de forma a representar os acontecimentos de um passado recente. Pedimos autorização para que o encontro fosse filmado para que todos os detalhes das conversas não fossem perdidos.

O objetivo que norteou a pesquisa foi o de analisar narrativas de professoras sobre aspectos da educação/formação continuada que tiveram a oportunidade de participar, evidenciando as lógicas de organização e compreensão que perpassaram os processos orientadores da educação/ formação da década recortada. A base teórica que orientou o estudo foi Benjamin (1985); Hall (1997); Bragança (2012); Ball (2002; 2005).

É importante frisar, que as professoras participantes têm formação superior em pedagogia e entre as nove, duas também exercem a função de coordenadora pedagógica. Com exceção dessas coordenadoras da escola que cedeu o espaço, ano a ano, assinam contrato temporário de trabalho com a rede municipal, em razão da escassez de concurso público para efetivação de contrato permanente. Argumentamos, embasadas pelas narrativas das professoras, que nos percursos de educação/formação continuada são predominantes lógicas que estreitam a compreensão do que é ser professor, orientados pela perspectiva da performatividade e do gerenciamento dos resultados do trabalho do professor e da escola.

Na primeira parte do artigo, exploramos o potencial das narrativas para a pesquisa e como elas possibilitam liberdade de expressão, para além de perguntas e respostas, sem que para tanto, adentre ao contexto psicológico do narrador e nem reduza a memória narrada à pobreza da informação. Ainda nesse primeiro sub-tópico abordamos a lógica de educação/formação que coloca os sujeitos como centrais no processo de construção educativo/formativo. Na segunda parte, apresentamos uma outra lógica que cultiva a educação/formação por outro horizonte e que pautam a organização e implementação curricular, estabelecendo uma relação direta e principal com a economia e com o gerenciamento de resultados. Por fim, analisamos as narrativas, utilizando como parâmetro essas duas lógicas de organização e implementação da educação/ formação continuada.

\section{NarRativa e eduCAÇÃo/FOrmação}

Nos inserimos na discursividade de Walter Benjamin para adentrarmos ao significado de narrativa. Esse filósofo da linguagem, ainda fortemente influenciado pela guerra de trincheiras, publica em 1936 o ensaio intitulada O narrador: considerações sobre a obra de Nikolai Leskov. Dessa obra, para além do seu olhar desesperançoso acerca da progressiva devastação das narrativas, nos interessa o potencial visualizado e analisado na obra de Leskov. Para Benjamin (1985), a obra desse escritor russo seria exemplo notável de um verdadeiro narrador. 
Em conformidade com o ensaio desse filósofo, símbolo da tradição alemã, principalmente a frankfurtiana, "o narrador retira da experiência o que ele conta: sua própria experiência ou a relatada pelos outros. E incorpora as coisas narradas à experiência dos seus ouvintes" (BENJAMIN, 1985, p. 201). Nas narrativas, o excepcional e o admirável são narrados com grande perspicácia e precisão. Por outro lado, o contexto psicológico do narrador não se expõe, não determina ao leitor/ouvinte esse estado de espírito. Eles ficam totalmente em liberdade para traduzir a história para além da informação, atingindo uma amplitude incomensurável. Nelas não existe o interesse em reproduzir o "puro em si da coisa narrada como uma informação, um relatório ou qualquer aspecto técnico. Ela mergulha a coisa na vida do narrador para em seguida retirá-la dele. Assim se imprime na narrativa a marca do narrador, como a mão do oleiro na argila do vaso" (BENJAMIN, 1985, p. 205), constituindo-se em uma maneira "artesanal de comunicação".

Destacamos que Benjamin (1985) estabelece uma relação entre o sujeito narrador e o sujeito artesão (oleiro), definindo os dois como artesões. Se o vaso é produto do oleiro; a narrativa é o produto do narrador. Referindo-se ainda sobre essa relação ele diz:

A antiga coordenação da alma, do olhar e da mão, que transparece nas palavras de Va-
réry, é típica do artesão, e é ela que encontramos sempre, onde quer que a arte de narrar
seja praticada. Podemos ir mais longe e perguntar se a relação entre o narrador e sua
matéria - a vida humana - não seria ela própria uma elação artesanal. Não seria sua
tarefa trabalhar a matéria-prima da experiência - a sua e a dos outros - transformando-a
num produto sólido, útil e único? (BENJAMIN, 1985, p. 221)

As professoras participantes da pesquisa atuaram como narradoras das suas trajetórias de educação/formação continuada ao longo da sua vida profissional, tendo como matéria-prima as experiências ocasionadas pelos cursos oferecidos pela Secretaria municipal de Educação. Não são exímias narradoras no sentido colossal, tal qual Benjamin (1985, p. 220-221) enxerga nas narrativas de Valéry sobre a aguçada e quase mística percepção do artista. No entanto, narraram com precisão, ao mergulharem em suas experiências de educação/formação, a partir do cenário de fotografias exposto na sala.

$\mathrm{Na}$ ocasião da tarde de conversa que tivemos com o grupo das professoras, ao olharem o cenário da mesa organizada com uma série de fotografias, em que o foco da lente instantaneamente clicou em episódios de cursos vivenciados pelas professoras da escola Wildy Viana das Neves, foi suficiente para mergulharem em suas experiências, passando a narrar com suas marcas pessoais o que haviam vivido à época, combinando esquemas das tradições que organizavam os cursos de formação "para" e não "com", as professoras. As narrativas evidenciaram acontecimentos presenciados por elas ou mencionados por outras, reelaboradas de maneira sólida, útil e única, com a marca de cada uma delas.

Para Benjamin (1985), o narrador ao evidenciar a sua experiência ou a contada por outros, explicita o senso prático das narrativas, às quais trazem junto sabedoria, constituindo o lado épico da verdade. $O$ pensador alemão concede ao narrador um senso prático, que se efetiva por intermédio da arte de dar conselhos. Sobre esse aspecto de seu pensamento, ele diz que a narrativa

tem sempre em si, às vezes de forma latente, uma dimensão utilitária. Essa utilidade pode consistir seja num ensinamento moral, seja numa sugestão, seja num proverbio ou numa norma de vida - de qualquer maneira, o narrador é um homem que sabe dar 
conselhos. [...] Aconselhar é menos responder a uma pergunta que fazer uma sugestão sobre a continuação de uma história que está sendo narrada. [...] O conselho tecido na substância viva da existência tem um nome: sabedoria (BENJAMIN, 1985, p. 200).

É nessa perspectiva que passamos a gravar as narrativas das professoras a respeito da trajetória de educação/formação continuada que participaram, no percurso de suas vidas profissionais de docentes da educação infantil, a fim de construir um material que possibilitasse entender as lógicas de educação/formação, utilizadas pela Secretaria Municipal de Rio Branco, na década vivida por essas professoras. O empenho foi o de compreender pelas narrativas, as trilhas sugeridas e o que elas podiam estar apontando sobre o processo de formação vivenciado por essa comunidade. Nesse horizonte, passamos na continuidade do texto, fazer uma inserção no que estamos compreendendo por educação/formação e sua continuidade, recorrentemente conhecida por formação continuada.

Observamos na literatura educacional que a palavra formação apresenta uma ambiguidade entre dinâmicas distintas, explicitando realidades diferentes e sua manifesta dificuldade semântica. Ora uma vertente indica o significado desse vocábulo como educação, entendendo como processo externo e prática social de formação em diferentes instituições; ora como transformação pessoal em que o indivíduo se constitui no trajeto de sua existência; ou ainda empregando a expressão como manifestação que resguarda os dois sentidos anteriores (BRAGANÇA, 2012). Diante desse embaraço, optamos em utilizar os dois termos ligados por barra (educação/formação) ao longo do texto, abrigando os dois sentidos.

Falar de educação/formação, necessariamente nos leva a resgatar os sujeitos para o eixo central das reflexões. Os sujeitos são históricos e educam-se/formam-se por meio das interações estabelecidas consigo mesmo, com o meio e com outros sujeitos, e todas essas interações são centralmente constituídas pela cultura. Nessa rede de relações, vão se substantivando por influências da época, dos significados contruídos, das representações e da globalização possibilitada pela revolução tecnológica das últimas décadas (HALL, 1997).

Assim, as interações entre sujeitos são constituídas pelas culturas e dentro desse caldeirão de interações culturais a educação/formação é forjada, significada, apropriada, ressignificada, criada e recriada em um contínuo permanente, formando jeitos de ser e de estar no mundo. Nesse aspecto, o processo educativo/formativo assistemático, aquele que se vive nas interações culturais nos nossos círculos de convivência, vai perdurar toda existência dos sujeitos. Por outro lado, o processo educativo/formativo pode ser também configurado, pensado metodicamente e articulado sistematicamente, de modo a alcançar os sujeitos em uma determinada direção, promovido por instituições que têm como missão efetivar esse desiderato, como por exemplo as escolas. Desse modo, essas duas conformações educativas/formativas se efetivam pela prática social, seja na vertente informal, pelo próprio decurso da vida, seja na vertente institucionalizada. Paralelamente a esse processo educativo/formativo interdependente, o conhecimento é produzido e compartilhado. Os sujeitos, permeados por esse amplo processo, vão redimensionando suas visões de mundo, atuando de forma crítica ou não crítica, propositiva e humana.

Para Bragança (2012) "o conhecimento como expressão da existência humana" (p. 777) determina processos reflexivos individualizados dos sujeitos, implicando necessariamente um 
ritmo qualitativamente desacelerado do cotidiano. Significa pautar-se pelo tempo kairós ${ }^{6}$, menos cronológico, menos absoluto e menos linear, que possibilita um voltar-se para si mesmo, dando sentido à vida e à sua existência. No entanto, esse voltar-se aos próprios fios da vida individualizada não significa o isolamento. Significa abrir-se ao outro e em conexão com o universo, a partir da busca de si, em relação dialética indivisível entre o "eu", o "outro" e o "nós" na constituição da educação/formação.

Por outra perspectiva, a educação/formação no sentido strictu sensu, ou mais especificamente a autoeducação/autoformação, se desdobra interiormente ligando-se à experiência particular do sujeito, pela e por influência do conhecimento e do saber. Assim, é possível inferir que em potencial os espaços e tempos de uma existência humana são também territórios e temporalidades de educação/formação e transformação. Se faz supor uma prática de conjecturas com o conhecimento, com o saber, em que se processam organizações e reorganização de sentidos frente à existência e à transformação pessoal. Por esse itinerário, o processo de inter-relação com o conhecimento e com o saber seria mais relevante que o próprio conhecimento e o saber (BRAGANÇA, 2012).

Desse modo, educação/formação seria organizar elementos diversos e dispersos em repertórios significativos a partir de dinâmicas singulares e pessoais, dando forma à totalidade de si mesmo e conduzindo à constituição de si próprio. Implica inúmeras relações de trocas, de aprendizagens, de interações sociais e de experiências incalculáveis, sem a possibilidade prévia e de explicitação objetiva, de modo a tornar possível a conferência exata dos seus resultados, uma vez que o processo é subjetivo.

Entender o conceito de educação/formação na perspectiva da autoeducação/autoformação, em que a subjetividade do sujeito é central, implica afirmar que a educação/formação é um processo interior em que esse agente (sujeito) se permite ser tocado pelos movimentos educativos/formativos da vida, significando-os e vivenciando experiências importantes de constituição. Por outro lado, é relevante explicitar que as experiências significativas, que são essencialmente educativas/formativas, tornam-se possíveis por serem da mesma forma coletivas. Os movimentos educativos/formativos que possibilitaram experiências significativas são provenientes de investimentos sociais, "no caso do processo escolar, ou das tramas, dos encontros e desencontros que temos com os outros e com o meio, ao longo da vida" (BRAGANÇA, 2012, p. 815).

Enfatizar a autoeducação/autoformação como processo interior e pessoal, demanda riscos, se justaposto a uma corrente ideológica que isola os sujeitos e os responsabilizam pelo seu processo de formação. É importante frisar, que nos posicionamos criticamente frente a essa abordagem. Embora reconheça e defenda que a autoeducação/autoformação necessariamente pressupõe a centralidade do sujeito, isto não implica na defesa da extinção e esvaziamento das políticas públicas de educação/formação, que desenham encaminhamentos de qualidade ao processo educativo/formativo formalizado nas escolas, possibilitando o acesso e permanência dos sujeitos nas organizações educativas públicas.

Significa colocar a centralidade do sujeito no processo educativo/formativo descolado das questões da empregabilidade, uma vez que essa vinculação inviabiliza a construção subjetiva da

6 "Kairos descreve uma noção peculiar de tempo, uma qualidade complementar àquela implicada na temporalidade representada por Cronos. Kairos refere-se a uma experiência temporal na qual percebemos o "momento oportuno" em relação a determinado objeto, processo ou contexto [...] É o melhor instante no presente. Ele representa um tempo não absoluto, contínuo ou linear" (GARCIA, 2000). 
aprendizagem e permite transpor para o plano individual o não acesso ao mundo do emprego, sendo ele próprio (sujeito) o responsável pelas vicissitudes da não empregabilidade. Nos distanciamos dessa perspectiva, entendendo a educação/formação formalizada nas escolas um investimento coletivo, evidenciando o sujeito no processo educativo/formativo, sendo ele o ponto de partida para a implementação das políticas públicas nas instituições educativas/formativas. Cultivamos, nesse sentido, posicionar o sujeito no centro do processo investigativo da formação como sujeito ativo, todavia, entendendo-o mergulhado em relações sociais e culturais e partícipe de uma comunidade aprendente, que o produz e concede sentidos ao seu projeto de educação/ formação (BRAGANÇA, 2012, p. 841).

Cabe nesta análise, articular essa compreensão ao que as narrativas docentes indicaram, vislumbrando até que ponto essa forma de dimensionar a educação/formação permeou o processo vivido pelas professoras. Por outro lado, convivemos na contemporaneidade com outra lógica de compreensão que cultiva a educação/formação por outro horizonte e que pautam a organização e implementação curricular, estabelecendo uma relação direta e principal com a economia e com o gerenciamento de resultados produzidos pelas instituições públicas, a qual passaremos a tratar na sequência.

\section{LÓGICA DE DESEMPENHO E DE RESULTADOS}

No bojo das discussões sobre educação/formação continuada, vale ressaltar aspectos que podem influenciar a prática do professor ao que se tem denominado de lógica de desempenho e de resultados. De acordo com Nosella, Buffa e Leal (2010, p.1), "desempenho" é sinônimo de "performance", visto que sua origem vem da língua francesa (parfournir), inserido na língua inglesa como "to perform", o que representa um conjunto de características ou competências ligadas ao rendimento de um indivíduo, um grupo ou uma organização que estão relacionados com o cumprimento de metas, resultados ou expectativas previamente determinado.

Seguindo essa trilha perspectivada por Ball (2005), afirmamos que há uma forte mudança em muitos dos aspectos que condicionam a educação/formação profissional dos professores. Se a educação/formação continuada está voltada a instrumentalizar os professores para o desenvolvimento da prática em sala de aula e para a manutenção da empregabilidade, estes passam a relegar seu processo de construção profissional (embasado em sua autonomia) para optarem pela

[...] forma de desempenho (performance), em que o que conta como prática profissional resume-se a satisfazer julgamentos fixos e impostos a partir de fora. Os critérios de qualidade ou de boa prática são fechados e completos - em contraste com "a necessidade de raciocínio moral e incerteza adequada" (LAMBEK, 2000) como características determinantes da prática profissional. (BALL, 2005, p. 542).

Por esse panorama, o significado do que é ser professor é reconfigurado e a educação/ formação continuada passa a ser desenhada a partir de critérios da racionalidade técnica, associados à vigilância do desempenho e às regras produzidas externamente aos sujeitos, que vivenciam o cotidiano das escolas. A produção dessa nova identidade do professor é moldada na educação/formação continuada, gerida a partir das políticas públicas não mais produzidas localmente, mas totalmente centralizadas e disseminadas para todo o território nacional. Nesse processo, a lógica de administração são instituídas e paulatinamente vão substituindo as lógicas 
que guiavam o fazer pedagógico das escolas. A introdução do gerencialismo no setor público traz inovações para a capilaridade de poder, que alteram as relações entre os sujeitos, dando outra conformação às práticas sociais do conjunto de professores nas instituições escolares.

Nesse contexto, as práticas sociais dos professores e dos outros profissionais das instituições públicas escolares, são permeadas por um conjunto de influências, talvez não percebidas claramente por eles, mas que efetivamente demarcam os encaminhamentos do que fazem nas escolas. Essas influências são forjados pelas políticas públicas e pela educação/formação continuada. De acordo com Ball (2005), apud Cunha, Marcondes, Leite (2015) é possível perceber, dentre outros aspectos, um conjunto dessas influências que norteiam a educação/formação e a prática docente:

1)A aprendizagem é representada como o resultado de uma política de custos-benefícios; 2) o conhecimento é definido de forma centralizada com critérios específicos e explícitos de modo a possibilitar a mensuração de seus resultados; 3) o êxito é compreendido como conjunto de "metas de produtividade"; 4) o trabalho alheio precisa ser gerenciado; 5) os sistemas éticos são introduzidos com base no interesse individualizado e não mais coletivo; 6) a competição é incentivada como garantia na produção da "qualidade"; 7) o professor tem que se tornar permanentemente "aprendiz" e "habilitado" a lidar com inúmeras situações de instabilidades que circundam as relações em um mundo global; 8) os professores são identificados como produtores/fornecedores, administradores e empresários da educação (CUNHA; MARCONDES; LEITE, 2015).

A economia e o gerencialismo passam a ser o centro a disseminar o modo, a forma e o tipo de avaliação mais apropriados, passando a normalizar a partir desses dois eixos, o que é uma boa prática pedagógica. O currículo é centralizado nacionalmente e é artefato relevante de controle, estando circunscrito aos interesses do mercado, da economia e da empregabilidade. A eficácia do trabalho escolar é medida pela performance de professores e alunos e das organizações. Mais alunos na escola, mais aprovação, mais dividendos econômicos a escola aufere.

A cultura da performatividade tem como intento transferir para os sujeitos e no caso do foco deste artigo, para os professores, toda a responsabilidade dos resultados atingidos pela escola, como também com o bem-estar da instituição. Criam-se significados que incutem um jeito de ser professor e de responsabilização centrada unicamente nesses profissionais. Assim, as ações das escolas, desempenhadas por professores, coordenadores e gestores precisam ser monitoradas pela Secretaria Mucicipal de Educação - SEME, que por sua vez é monitorada pela Secretaria Estadual de Educação - SEE e esta, monitorada pelo Ministério da Educação - MEC, que no caso, tem contas a prestar aos organismos internacionais, que afere o nível de "qualidade" da educação brasileira, criando uma cadeia de controle extremamente potente da educação nacional. Ball (2002), consegue explicitar como as reformas educacionais, iniciadas na década de noventa do século passado, têm sido eficientes no sentido de reestruturar o papel dos sujeitos nos sistemas educativos, na medida que internalizam a importância do cumprimento das metas impostas externamente, mas que regulam todo o funcionamento dos sistemas educacionais dos países, considerados em desenvolvimento.

Dessa forma, a prática do professor, em um contexto de performance, será avaliada pelos resultados solicitados pelas instituições reguladoras, nesse caso a SEME, SEE, MEC com base nesses resultados, os professores podem ser rotulados como bons ou ruins. Assim, novos papeis e subjetividades são produzidos, com professores sendo transformados em produtores de resul- 
tados, bem como fornecedores, empresários da educação e administradores. Os docentes ficam então sujeitos à avaliação e às análises periódicas, além da comparação entre o desempenho de seus colegas (BALL, 2005).

Entretanto, é arbitrário classificar os docentes a partir de resultados fechados, desconsiderando outras tantas situações vivenciadas na sala de aula. Realizam os julgamentos a partir de evidências registradas, as quais não dão conta de compreender os vários aspectos da sala de aula, dos alunos e do contexto em que estão inseridos.

Diante disso, os professores ficam sujeitos a "fornecer" um conhecimento atrelado aos resultados, atendendo aos propósitos de uma "educação resultante de supostas exigências funcionais ou instrumentais, não de objetivos pessoais, culturais ou politicas" (MULLER, 1998, p. 188 apud BALL, 2005, p. 548). Nessa direção, Ball (2005, p. 554) completa o propósito da performatividade docente indicando que:

Cada vez mais, escolhemos e julgamos nossas ações, e elas são julgadas por outros, com base na contribuição que fazem para o desempenho organizacional, apresentado em termos de resultados mensuráveis. As crenças não importam mais - é a produção que conta. As crenças fazem parte de um discurso ultrapassado, cada vez mais fora de lugar (BALL, 2005, p. 554).

Ball (2005) esclarece que, essa visão traz para a educação básica um novo tipo de professor, influenciado por novos tipos de conhecimentos, são "invocados" pelas mudanças no contexto educacional, um professor capaz de maximizar o desempenho e que, ao mesmo tempo, seja capaz de secundarizar seus princípios, antes fundamentais, para considerar a excelência e o aperfeiçoamento como as grandes forças de sua prática.

Assim, com esse quadro analítico, passamos a explicitar as narrativas das professoras, procurando evidenciar as lógicas de organização e compreensão que perpassaram os processos orientadores da educação/formação da década recortada. Como bem nos orienta Benjamin (1985) e Sarlo (2007), temos consciência que as narrativas são produzidas pela memória e são atualizadas no presente. "Poderíamos dizer que o passado se faz no presente. E a lembrança precisa do presente porque [...] o tempo próprio da lembrança é o presente, isto é, o único tempo apropriado para lembrar e, também, o tempo da lembrança se apodera" (SARLO, 2007, p. 10).

\section{NarRativas das PROFESSORAS}

As lembranças emergiram a partir do impulso do presente, provocado pela indicação das pesquisadoras que solicitaram ao grupo que narrassem suas histórias de educação/formação, suas concepções e impressões a respeito do que viveram sobre o letramento. Nesse sentido, o eixo central das narrativas focalizaram a temática do letramento nos cursos que participaram. No entanto, o que foi extraído para esta análise, foram os trechos que se mostraram significativos e centrais para o objetivo deste artigo. Assim, caminhando pelas margens das empirias coletadas, suscitadas nas narrativas, que esse artigo foi construído.

Para narrarem sobre a temática do letramento percorreram um longo caminho pela educação/formação oferecidas primeiramente pela Secretaria Estadual de Educação - SEE e posteriormente, com a municipalização da Educação Infantil, desdobraram-se nos processos educativos/formativos ministrados pela Secretaria Municipal de Educação de Rio Branco - SEME/ $\mathrm{RB}$. No tabuleiro dessas memórias narradas, a professora Aline iniciou recordando como eram 
as formações continuadas. Ao começar a sua narrativa, teve o cuidado de dizer que não sabia se "as meninas" tinham essas mesmas recordações, conforme podemos observar no relato a seguir:

Eu lembro que a nossa formadora era uma técnica da SEME, eu não sei se as meninas lembram, mas essa formadora compartilhou muitas aprendizagens. Era na UNINORT com as professoras da pré-escola e de lá pra cá eu creio que não mudou muita coisa não (Aline).

A professora narra com encantamento a sua primeira formação com as técnicas da SEME, evidenciando as aprendizagens que foram compartilhadas. Mas finaliza, com a crença de que o formato dessas primeiras formações permanece até o presente, evidenciando que as orientações perduram e ficaram centradas em uma proposta externa, suscitadas a partir da década de noventa, quando o processo de reformas da educação brasileira iniciaram a sua conformação e passaram a determinar as reformas locais. Esclarece que as formadoras eram as técnicas da SEME, mas fica a pergunta quem seria a formadora dessas formadoras? E por que será que a professora, que continua no sistema, trabalhando em uma creche municipal diz que "não mudou muita coisa não".

$\mathrm{Na}$ mesma direção da professora Aline, a professora e coordenadora pedagógica Jemille acrescenta que os materiais utilizados nesse processo de educação/formação, continua tendo a mesma estrutura até os dias de hoje, sob a responsabilidade da SEME. Que todo o processo se organiza em torno do que já vinha, há algum tempo, sendo desenvolvido pela equipe técnica da educação infantil da SEE, não sendo diferente da época em que a escola pertencia à rede estadual, afirmando que foi a equipe da SEE a primeira a investir na educação infantil de Rio Branco. Em sua narrativa explicita com quem trabalhavam e o ponto de partida que desencadeava toda a formação, evidenciando a centralidade curricular e a cadeia de educação/formação e de controle que orientam as práticas sociais das técnicas nas secretarias, sejam elas no MEC, na SEE e SEME. Isso pode ser explicitado no trecho da narrativa de Jamille:

Nós tínhamos os Referências Curriculares da Educação Infantil, que tinha acabado de
chegar a Rio Branco 99-2000, nós ainda em 2006 degustávamos mesmo os RCNEI, nós
pegamos aquelas técnicas da SEE, aquela primeira da Secretaria da Educação Infantil,
a primeira equipe que começou a investir na educação infantil aqui em Rio Branco. Nós
já tínhamos a estrutura que temos hoje na SEME com aquela equipe que era da SEE,
nós tínhamos a formação com essa equipe da secretaria e tínhamos a formação na escola
uma vez por mês. (Jemille)

Neste trecho da narrativa a coordenadora pedagógica consegue datar o período de chegada do RCNEI- Referencial Curricular Nacional para Educação Infantil, e o tempo que levaram para estuda-lo. É importante perceber de onde fala, do lugar que ocupa, do seu olhar para o RCNEI. O sentimento que traz em sua narrativa é de quem havia se alimentado e o alimento era o saber encontrado no RCNEI. É interessante a metáfora usada para dizer que este estudo tinha sabor, ainda estavam degustando em 2006.

Permeia em sua fala certa admiração em relação às técnicas da SEE, que segundo sua interpretação, foram as primeiras a investir em formação para Educação Infantil. Com a equipe da SEE passaram a conhecer a estrutura da educação/formação, primeiramente acontecia com a

7 Termo utilizado pela professora Aline para se referir às demais professoras que estavam presentes. 
coordenadora e posteriormente com as professoras na escola. Não há nesta narrativa uma resistência ao programa que naquela época se estabelecia e sim a satisfação de ter um investimento para essa modalidade infantil. Se antes a educação infantil era mais livre e os professores coletivamente tinham autonomia para criar o caminho trilhado em suas escolas, pouco é evidenciado pela professora. Percebemos um aceitação acrítica por parte da professora, do que passou a se constituir a educação infantil na contemporaneidade.

A coordenadora Jemille faz uma comparação entre as formadoras das secretarias, ao relatar que esse modelo de formação da SEE foi copiado pela SEME como um novo jeito de formação continuada, porém, ressalta que quem havia participado na SEE já conhecia a dinâmica dos encontros formativos. Mas também não percebe que esse modelo foi produzido fora do âmbito da SEE, que foi um modelo externo que chegou e que foi absorvido e disseminado para as escolas.

Seguem explicitando a dinâmica de funcionamento da educação/formação continuada, que tinha como alvo inicial o trabalho com os coordenadores pedagógicos, processado em ambiente fora da escola. Com os professores havia dois formatos de organizar os estudos, internamente e em espaços externos. Após o retorno desse grupo de coordenadores às escolas, os temas passavam a ser desenvolvidos e abordados nos grupos de estudo ${ }^{8}$ de professores, com as orientações e acompanhamento das coordenadoras pedagógicas, que aconteciam no próprio ambiente da escola. Quando os estudos aconteciam com a equipe da SEME, se processava o dia todo e em ambiente espaçoso que acomodasse os professores das escolas infantis de todo o município, conforme explicita a professora Aline em outro trecho da sua narrativa.

\begin{abstract}
A formação na escola eram os grupos de estudo. A gente sentava na segunda-feira para planejar, na terça-feira tinha a sistematização e na quinta-feira fazia o grupo de estudo com a diretora que era nossa coordenadora também, toda quinta-feira sentava para o grupo de estudo de uma hora, duas horas né? E no final do ano quem pedia certificado ela até fazia com os temas trabalhados. Às vezes acontecia nos sábados aquele grupão quando não reunia na quinta-feira. $\mathrm{E}$ a formação com a formadora da SEME era o dia todo, no período da manhã e no período da tarde (Aline).
\end{abstract}

É importante observar nesse excerto narrativo, que a professora revela a organização do planejamento semanal e que a educação/formação continuada se processava por dentro do grupo de estudos. Mas o tema de estudo nesse primeiro momento não entrou na discussão, no entanto, vem a tona um aspecto importante que faz parte da cultura da performatividade, e que se expressa pela política de produtividade e de bonificação, comprovada pelo número de alunos aprovados, quantidade de certificados/títulos e metas alcançadas. Atribuir certificado pelo planejamento e estudos realizados no interior da escola é um aspecto introduzido pela política produtivista das reformas, o qual o professor comprova sua eficiência e conhecimento pela quantidade desses aspectos que conseguiu alcançar.

Em outras narrativas algumas professoras expõem suas primeiras experiência com a educação/formação continuada, às quais não ocorreram com as técnicas das secretarias SEME ou SEE e sim com a equipe do Instituto Abaporu' ${ }^{9}$ A exemplo disso, a professora Reinara, relembra

8 Grupo de estudo é a metodologia usada pelas escolas para realizar a formação continuada. O coordenador participa de uma formação dada pelos técnicos das secretarias de educação e multiplicava na escola.

9 Instituto Abaporu de Educação e Cultura foi contratado pela SEE e SEME para desenvolverem um programa de educação/ formação continuada para professores e coordenadores pedagógicos no município de Rio Branco e demais municípios do Estado do Acre. 
a vivência dos encontros de formação que mais pareciam reuniões de categoria profissional, pela multidão que se aglomerava em grandes espaços. Todos os coordenadores pedagógicos e professores das escolas de educação infantil eram convocadas a participarem no mesmo dia e local. Logicamente, os custos com o formador que vinha de fora tinha que ser representativo e equilibrado entre custo-benefício. Quanto mais tempo esse formador ficasse na cidade para atender os professores por escola, maiores seriam as despesas econômicas e o equilíbrio entre custo e benefício ficava fora dos parâmetros que guiam a política de educação/formação.

\begin{abstract}
Eu não consigo lembrar nessa época das formadoras, e lembro bem da Abaporu, não era planejamento, era uma reunião geral que tinha que ir todo mundo lá pro teatrão e tinha uma professora bem forte que vinha de São Paulo, lembro vagamente que tinha uma formação para coordenadora que participava na Secretaria e repassava pra gente na escola. Mas formação como a gente vai hoje à secretaria, assim naquela época não tinha. Era mais quando vinha à formadora da Abaporu (Reinara).
\end{abstract}

Barroso (2004, p. 53) nos ajuda a compreender esse modo uniforme de organização da política de educação/formação continuada no Brasil, ou seja, "este modelo caracteriza-se, fundamentalmente, pelo princípio da homogeneidade", em que o olhar do formador que vem de fora não percebe as diferenças e as necessidades do que é local. Assim, o mesmo tema desenvolvido em qualquer outra localidade serve também para este ou aquele lugar.

Em outras palavras, é o que a professora Reinara diz, que todos os professores, de todas as escolas tinham que comparecer ao teatrão, que vinha uma professora de outro Estado e massificava informações, sem considerar a pessoa do professor, suas representações, seus significados, seu ambiente de trabalho, seus saberes e o modo que transformavam esses saberes em ação pedagógica. Ainda sobre as formadoras, a coordenadora pedagógica Daniela recorda o período em que era professora e o percurso que trilhou na formação orientada pela SEME, através do Instituto Abaporu:

Quando iniciei como professora de creche, as minhas formações eram à noite com o pessoal da Abaporu, a Rosana Dutoit, foi a formadora durante um ano e no final recebemos o certificado, a gente fazia no SEBRAE, na prefeitura e em vários lugares. Foi a Rosana que formou essa turma de creche quando eu iniciei e eu gostava muito das formações dela, porque ela era bem específica, ela trabalhou formações sobre o brincar, sobre letramento que foi bem específica pra creche, eu gostei muito e eu recebi um certificado específico da Abaporu com 360h de formação, a gente trabalhava o dia todinho na creche (sorriu) aí todo mês a gente saia um dia um pouquinho mais cedo, pra $18 \mathrm{~h}$ já está na formação (Daniela).

Referindo-se ao que vivenciou no passado a coordenadora Daniela, procura reconstruir o percurso de sua educação/formação, do esforço pessoal para participar dos encontros e da docilidade em aceitar tudo que era repassado por se tratar de temas específicos ligados a prática na educação infantil. É importante ressaltar em sua narrativa que Daniela gostava das formações, especificamente pelos temas próprios para creche. Deixa transparecer uma gratidão, por ter tido a oportunidade como professora iniciante participar de encontros específicos para creche, com uma formadora da Abaporu que ao final de um ano certificou os professores e professoras que participaram.

Essa narrativa focaliza que os professores, participantes dessas formações, recebiam treinamento, capacitações para o desempenho das atividades educativas, adquirindo o conjunto de 
competências a serem empregadas para a condução desta política de custo-benefício. Essa compreensão de educação/formação está ancorada em uma análise do termo, ou seja, a complexidade das atividades produtivas requer pessoas que dominem saberes específicos para responder às demandas das exigências dessa produção, em outras palavras a cultura do desempenho. Com isso o termo formação carrega um caráter pragmático e utilitário, ou seja, um "treinamento não intelectualizado, baseado na competência. Os professores são pensados e caracterizados de novas maneiras: cada vez mais são pensados como técnicos em pedagogia", estritamente embasada na perspectiva da racionalidade técnica de educação (BALL,2005, p.548). Estrategicamente, tudo é pensado fora do âmbito dos contextos locais, uma vez que ao professor cabe aprender e cumprir determinações técnicas, emanadas do exterior da escola, reduzindo o ângulo de compreensão do que é ser professor. Por outro lado, não menos importante, são gerenciados, bonificados e publicizados a partir da performance que eles e a organização escolar apresentam a cada periodicidade de avaliação externa, e dessa forma, serem reconhecidos como aptos ou não de serem considerados bons professores e de escola de boa qualidade.

Ainda sobre educação/formação, a professora Aline pediu a palavra e reconstruiu o que havia dito anteriormente "de lá pra cá não mudou muita coisa não". As diversas vozes fizeram com que ela reelaborasse sua narrativa:

Lembro também das formações em 2010 é que não era como é hoje que levam um tema, as atividades que a gente faz. Antes era assim: a gente discutia nossas experiências que vivia na sala de aula, como se elas tivessem coletando tudo aquilo ali todos aqueles momentos nossos para fazer a proposta pedagógica, tanto que a proposta foi toda feita dentro das experiências vividas durante as formações. (Aline).

Esse movimento aparentemente contraditório é um complemento ao que havia dito. Trata-se de mais uma memória que foi reconstruída a partir do discurso do outro. Mas o interessante é como a professora diz que "não era como é hoje" ela não está falando da estrutura da formação como no seu primeiro depoimento, aqui ela trata dos temas de estudo. O tema e a significação são palavras que se diferenciam conforme o enunciado do locutor, o que foi dito não pertence mais aquele que disse, pode ser até o mesmo assunto, mas o significado é diferente porque o lugar de onde partiu não é o mesmo.

Cada programa de educação/formação é datado e sua tessitura é política e ideológica e por vezes tecem o novo sem mudar as velhas práticas. Temos como exemplo a narrativa da professora Jéssica que relata a metodologia das formadoras e a forma como resolviam os conflitos durante os encontros de formação, realizados pelas técnicas da SEME.

Eu tive oportunidade de participar de duas formações pela SEME o ano passado que teve como tema o Educar e o Cuidar, foi dada por duas formadoras da equipe de educação infantil da SEME. Geralmente elas levam a proposta que é a base do estudo e levam textos, fragmentos de textos da proposta, entregam para os grupos que estudam e depois falam do que leram para as outras colegas, é uma forma mais rápida de todo mundo ter acesso a grande parte da proposta pedagógica. E... o ano passado eu senti que elas ficavam muito na teoria ali dentro da proposta e nossas discussões do dia a dia de certa forma eram deixadas de lado, até mesmo porque com essas duas formadoras muitas coisas geravam polêmicas porque não sei ... de certa forma eles não aceitavam determinadas ideias (as professoras presentes confirmaram com a cabeça ou dizendo era assim mesmo) elas são resistentes mesmos, acho que faz bastante tempo que nem 
entram numa sala de aula e pensam que as coisas hoje são da mesma forma que eram quando elas estavam na sala de aula (Jéssica).

A professora Jéssica, em sua narrativa, demonstra uma visão crítica sobre a didática usada pelas técnicas da SEME, forma como eram trabalhados os temas vinculados à proposta curricular. Em seu dizer, eram fragmentos de textos, distribuídos a cada grupo de professoras, e após a apresentação de cada parte do texto pelos grupos, todos teriam "acesso a grande parte da proposta". Possivelmente, nesse fragmento específico da narrativa, a professora Jéssica, nos faz refletir que nem todos os professores tinham a leitura e compreensão da proposta curricular e que essa prática de estudo ficava no campo da teoria, entendendo esse termo como processo sistemático de produção do conhecimento, mas distante da compreensão daqueles sujeitos. Dessa forma, a professora Jéssica, afirma que "as discussões do dia a dia eram deixadas de lado". Percebemos, nessa pequena passagem de sua narrativa, um deslocamento, quem sabe uma fissura para pensar a respeito de uma educação/formação continuada de professores, que não considera em sua pauta de discussão a prática pedagógica vivida na escola, os saberes da pessoa do professor, suas dificuldades e tampouco as representações simbólicas desse ser docente, evidenciando que os professores não são centrais e nem ponto de partida para o desdobramento da educação/ formação que vivenciavam.

Podemos observar no reposicionamento da professora Jéssica sobre as duas formadoras, que a princípio eram cercadas de metodologias para conduzir a formação, mas as situações conflituosas geravam polêmicas, e a partir desse ponto, imperava a intolerância e a indiferença. É evidenciado que a memória das formadoras sobre terem sido algum dia professoras, cai completamente no esquecimento.

É possível perceber nessa narrativa uma indignação da professora Jéssica, ao dizer que as formadoras eram "resistentes" e provavelmente pelas suas posturas, fazia muito tempo que não habitavam uma sala de aula. Essa postura descarta possibilidades de interação entre os interlocutores, evidenciando-se um monólogo, beirando quase que um autoritarismo por parte das formadoras. Nessa relação há um único tipo de discurso, o qual não é permitido questionar ou discutir, levando ao apagamento do outro, que é professor e deveria ser o centro do processo educativo/formativo.

É expresso no discurso de Jéssica sentidos que indicam descontentamento com a concepção de formação que distancia a prática cotidiana que acontece na escola de um ideal concebido dentro de gabinetes, a partir de referenciais teóricos descontextualizados. Sua narrativa é atravessada de sentidos que evidencia que as professoras pensam, questionam, constroem conhecimentos, leem, relacionam discursos e práticas em um contínuo processo dialógico. A reflexão da professora é uma crítica ao único discurso válido, o da formadora que reproduz possivelmente um discurso oficial ou não, mas que tem a pretensão de silenciar saberes, como se as professoras nada soubessem e vivessem em redomas fixas e inalteradas.

A cada narrativa das professoras e coordenadoras, surgiam elementos de reflexão que atravessam o objeto de estudo, como a emancipação, autonomia docente e práticas mais democráticas para a escola. Exemplo disso, é a narrativa da professora Regiane sobre o acompanhamen- 
to $^{10}$ na sala de aula. Esse discurso não surgiu do nada, não estava ali, existiu primeiramente na formação para coordenador pedagógico. E cada professora concebia com um sentido diferente.

Eu vou falar um pouquinho de 2012 e 2013. Em 2012 as formações aconteciam no Mira Shopping naquelas salas do último piso se não me engano, e todas as formações estavam dentro da proposta, elas tinham criado naquele momento. E o que acontecia eu lembro bem que era colocado no momento aquela discussão sobre a coordenação ir assistir a aula do professor e muitas vezes os professores se mostravam, como eu posso dizer... se mostravam resistentes a essa prática que elas queriam que isso acontecesse e eu lembro bem que em 2013 quando a Coordenadora Daniela já era até coordenadora e foi acompanhar a formação lá no Menino Jesus que a formadora pediu uma fala e a nossa coordenadora falou que ela vinha pra sala sim assistir as aulas, mas tinha momentos que ela aprendia muito mais com a professora do que ela contribuía como coordenadora...você lembra disso? (a coordenadora confirma) e a formadora até elogiou "viu gente é uma troca de conhecimentos" porque naquele momento isso era visto como um controle em que se vigiava... então tinha toda uma repercussão entre os docentes. ( Regiane)

A concepção da professora Regiane, revelada em sua narrativa sobre acompanhamento e as estratégias que o constituem, é atenuada, trazendo as marcas de um processo conflitivo sobre o que deve ser acompanhamento nas salas de aula. A partir do relato da professora e coordenadora pedagógica, a formadora, (no dizer da professora Regiane elogia dizendo "viu gente é uma troca de conhecimentos"), triunfa com a ideia do acompanhamento colocando/recolocando o professor no lugar de docilidade, silenciando seus questionamentos e desconfortos por se sentir controlado. Com essa concepção, a professora parece pensar diferente de outros enunciados que integram os discursos sobre acompanhamento.

Diante disso, compreendemos que o discurso da professora Regiane está também delineado no da formadora. Mas a própria professora deixa revelar as marcas de outras vozes discursivas, sobre essa prática criada pela Secretaria, denominada acompanhamento. Esse acompanhamento não se restringia somente a prática em sala de aula, as coordenadoras pedagógicas também eram acompanhadas pelas técnicas da SEME, como relata Jemille:

Eu lembro que naquela época eu fui aprender a fazer registro na educação infantil devido a equipe da educação infantil que queria ver essas evidências, não deixa de ser uma cobrança. Eram registros reflexivos e descritivos. Então toda formação que participávamos tínhamos que fazer esse registro escrito, os grupos de estudo, os planejamentos, os projetos e as sequências, tudo que era feito na escola era feito através do registro reflexivo/descritivo reflexivo. Elas faziam sim visitas na escola era mais reduzido, não sei como está hoje, e manuseavam e olhavam esses registros, verificavam as evidências, se estavam de acordo com as formações que elas repassavam, ainda mais naquela época que elas queriam que as teorias que estavam sendo divulgadas, analisadas elas queriam que fossem implementadas. Tinha sim e a gente sentia essa cobrança, senão nós não teríamos metas na escola e a equipe da educação infantil foi ela que realmente implementou, implantou tudo isso que começou mesmo. Nós tínhamos uma rotina, nós sempre tivemos que ter um plano de aula organizado, eu sou prova viva disso, sempre teve que ter e sempre guardar essas evidências porque elas passavam para fazer esse acompanhamento (Jemille).

$\overline{10} \mathrm{O}$ acompanhamento é uma prática realizada pelo coordenador (a) pedagógico na sala de aula do professor (a), ambos planejam e entram em acordo para o dia e a hora em que o coordenar (a) irá observar sua aula. Existe também o acompanhamento que as técnicas da SEME fazem na escola, nessa oportunidade elas observam o trabalho do coordenador pedagógico através de evidências escritas. 
A narrativa da coordenadora Jemille reforça a ideia de controle e cobrança pela SEME. Exemplo disso é o cuidado que ela tem em registrar todas as atividades desenvolvidas na escola para que durante o acompanhamento feito pelas técnicas, possa ser verificado o trabalho da coordenação, comprovando a partir das evidências escritas. É relevante destacar alguns trechos dessa narrativa. Ela deixa bem claro que essa equipe da SEME visitava a escola para verificar se as evidencias registradas estavam de acordo com as orientações dadas aos coordenares durante a formação. E ainda recoloca a ideia de cobrança enquanto um sentimento que permeava sua prática e acrescenta "senão nós não teríamos metas na escola", com certa tristeza, possivelmente por pensar diferente, ela diz em dois momentos que foi a equipe de educação infantil que criou essa prática. Ainda sobre o acompanhamento a professora Regiane complementa:

Eu lembro dessas visitas, um dia eu estava desenvolvendo uma roda de conversa e fui pega de surpresa com a presença delas e elas se surpreenderam com as crianças no momento porque instigaram as crianças e elas iam falando...falando...foi um momento bem bacana. Eu vi que elas saíram bem satisfeitas (Regiane).

A coordenadora Daniela, após a narrativa da professora Regiane, acrescentou:

Eu fiquei mais satisfeita, (antes de continuar sorriu para a professora Regiane) me sentia realizada com o desempenho das crianças na presença das técnicas da educação infantil da SEME. O retorno esperado foi evidenciado concretamente a partir dessa visita. Ao escrever meu relatório semestral, descrevi a situação citada como um resultado exitoso do acompanhamento (Daniela).

A partir dessa narrativa a coordenadora deixa transparecer uma intencionalidade em colocar as técnicas da secretaria na sala da professora Regiane, provavelmente por conhecer o trabalho de cada professora e saber o que as técnicas queriam ver.

Podemos observar a presença de uma ambivalência nas narrativas das professoras e coordenadoras pedagógicas sobre o acompanhamento, revelando, com isso, o cuidado em interpretar o que diz as narradoras, o que parece de antemão contraditório deixa de ser quando colocamos como parte de uma mesma história. Respeitar a opinião dos sujeitos dessa pesquisa é considerar a historicidade de cada uma delas, suas trajetórias e subjetividades que caracterizam os sentidos e significados que atribuem à educação/formação continuada.

Para concluir, evidenciamos que a lógica de organização e compreensão que perpassou os processos da educação/formação continuada da década recortada para análise, foi predominante aquela que toma como princípio a racionalidade técnica, o gerenciamento do desempenho e a performance da qualidade. Há uma clara intencionalidade de construir processos de subjetivação dos sujeitos (professores), em uma direção que naturaliza o desempenho da escola de qualidade, essencialmente próximo da economia e das necessidades de empregabilidade demandadas pelo campo empresarial. Essas estratégias muito bem articuladas, representam um tipo de qualidade determinada que norteia, afere e julga o valor da educação/formação, dos sujeitos e das organizações escolares a partir desses parâmetros.

Com a análise das narrativas, foi possível compreender que o processo educativo/formativo vivenciado e narrado pelas professoras, obedecem a essa lógica performática, que evidencia menos a melhoria da qualidade da ação pedagógica desenvolvida pelos professores em um sentido mais amplo e a partir das suas necessidades educativas/formativas e mais pelos resultados do sistema educacional. Mas para além dessa visualização, cumprem principalmente a 
determinações que direcionam para o alcance de um desempenho que viabilize muito de perto o controle e a gestão dos resultados a serem alcançados, almejados por organismos econômicos internacionais que faz acontecer uma nova ordem mundial, caracterizada pela responsabilização individualizada dos resultados.

\title{
NARRATIVES OF TEACHERS: CONTINUED EDUCATION/TRAINING IN TIMES OF CURRICULAR CENTRALISM
}

\begin{abstract}
The article was constructed from a cut of the narratives explained in a research developed in the period 2017-2018 with teachers from the municipal education network in the municipality of Rio Branco - Acre. It is the result of a qualitative research approach, in which the sources of information were teachers brought together in a focus group, to narrate their perceptions about their continuing education/training processes. Nine teachers participated in the group, aged between 25 and 41 years old and variable time of effective exercise in the teaching profession. The objective that guided the research was to analyze teachers' narratives about aspects of continuing education/training that had the opportunity to participate, showing the logic/s of organization and understanding that permeated the education /training processes of the cut decade. The theoretical basis that guided the study was Benjamin (1985); Hall (1997); Bragança (2012); Ball (2002; 2005). We argue, based on the teachers' narratives, that in the pathways of continuing education /training there are predominant logics that narrow the understanding of what it means to be a teacher, guided by the perspective of performativity and management of the results of the work of the teacher and the school.
\end{abstract}

KEYWORDS: Narratives. Continuing education-training. Performativity.

\section{REFERÊNCIAS}

BALL, S. J.. Reformar escolas/Reformar professores e os terrores da performatividade. Revista Portuguesa de Educação. Braga, Portugal, ano/vol. 15, n. 2, p. 3-23, 2002. Disponível em: http://josenorberto.com. br/BALL.\%2037415201.pdf. Acesso em: 13/08/2019.

BALL, STEPHEN J. Profissionalismo, gerencialismo e performatividade. Cad. Pesqui. [online]. 2005, v.35, n.126, p.539-564. Disponível em: www.scielo.br/pdf/cp/v35n126/ a02n126.pdf. Acesso em: 08 jul. 2019.

BARBOSA, Lazzari Leite. (Org.). Trajetórias e perspectivas da formação de educadores. São Paulo: Editora UNESP, 2004.

BENJAMIN, Walter. O narrador: considerações sobre a obra de Nikolai Leskov. In. Magia e técnica, arte e política. São Paulo, Brasiliense, 1985.

BRAGANÇA, Inês Ferreira de Souza. Histórias de vida e formação de professores: diálogos entre Brasil e Portugal. [online]. Rio de Janeiro: Euerj. 2012.

CUNHA, Viviane G. P. da; MARCONDES, Maria Inês; LEITE, Vânia F. Ângelo. Formação da identidade do professor no cenário das políticas locais de centralização curricular. São Paulo, Revista e-Curriculum, v. 13, n. 04, p. 683-710, out.-dez 2015. Disponível em: http://revistas.pucsp.br/index. php/currículum. Acesso em 20/05/2020.

GARCIA, Joe de Assis. Interdisciplinaridade, tempo e currículo. Tese (Doutorado) - Pontifícia Universidade Católica de São Paulo, São Paulo, 2000.

GATTI, Bernardete Angelina. Grupo focal na pesquisa em ciências sociais e humanas. Brasília, Líber Livros, 2005.

HALL, Stuart. A centralidade da cultura: notas sobre as revoluções culturais do nosso tempo. Educação e realidade, julho/dezembro 1997.

NOSELLA, P.; BUFFA, E.; LEAL, L.L.L. Cultura do desempenho. In: OLIVEIRA, D.A.; DUARTE, A.M.C.; VIEIRA, L.M.F. DICIONÁRIO: trabalho, profissão e condição docente. Belo Horizonte: UFMG / Faculdade de Educação, 2010. Disponível em: http://gestrado.net.br/pdf/398.pdf. Acesso em: $21 / 11 / 2019$.

SARLO, B. Tempo passado: cultura da memória e guinada subjetiva. Tradução de Rosa Freire D’Aguiar. São Paulo: Cia das Letras/Belo Horizonte: Editora da UFMG, 2007. 